\title{
Reflexiones en torno a la política pública de vivienda en Chile: entre el proceso y la mercancía, entre lo técnico y lo social
}

\author{
Alejandra Sofía Rivas Espinosa ${ }^{1}$
}

Fecha de recepción: 17 de octubre de 2016

Fecha de aprobación: 23 de noviembre de 2016

\begin{abstract}
Resumen
El presente artículo expone una reflexión sobre las especificidades del proceso de mercantilización de la vivienda social en Chile, analizando particularmente la concepción mecánica del hábitat y la consecuente descomposición de la vivienda en dimensiones técnicas constructivas, por un lado, y sociales, por el otro, junto con el desconocimiento de otros antecedentes, diferentes a los propuestos desde el conocimiento en el que se ampara la política pública. Teniendo en consideración esta dicotomía que marca la ejecución de la política de vivienda chilena, se tematiza el rol del discurso experto en la naturalización de las soluciones habitacionales propuestas, en la justificación de sus formas de producción y en la opacidad de su estrecha relación con las lógicas económicas dominantes, logrando con ello separar a las personas del diseño del hábitat residencial.
\end{abstract}

Palabras clave: política habitacional, vivienda social, vivienda-mercancía, conocimiento técnico, habitar

\section{Reflections on housing public policy in Chile: between the process and the goods, between the technical and the social}

\begin{abstract}
This article presents a reflection on the specificities of the process of commodification of social housing in Chile, analyzing, particularly, the mechanical conception of habitat and the consequent decomposition of the houses in technical constructive dimensions, on one hand, and social, on the other; along with the ignorance of other knowledges, different from those proposed in the knowledge that protects the public policies. Considering this
\end{abstract}

Licenciada en Sociología y Magíster en Urbanismo por la Universidad de Chile. Estudiante del Programa de Doctorado en Ciencias Sociales de la Universidad de Chile, becaria CONICYT (Doctorado Nacional 2015). Contacto: alejandrasofiarivasespinosa@gmail.com. 
Reflexiones en torno a la política pública de vivienda en Chile: entre el proceso y la mercancía, entre lo técnico y lo social - Rivas

dichotomy that marks the execution of the Chilean housing policy, it presents the role of the expert discourse in the naturalization of the proposed housing solutions, in the justification of its forms of production and in the opacity of its close relation with the dominant economic logics, thereby separating people from the design of the residential habitat.

keywords: housing policy, social housing, housing-commodity, technical knowledge, live.

\title{
Reflexões sobre a política pública de habitação no Chile: entre o processo e a mercadoria entre o técnico e o social
}

\begin{abstract}
Resumo
O presente artigo expõe uma reflexão sobre as especificidades do processo de mercantilização da habitação social no Chile, analisando, em particular a conceição mecânica do habitat e da consequente decomposição da morada em quanto a dimensões técnicas de construção, por uma parte, e sociais, pelo outro, juntamente com a falta de outras noções, diferentes as propostas desde o conhecimento onde a política pública se baseia. Considerando esta dicotomia que marca a execução da política habitacional chilena, tematizase o papel do discurso experto na naturalização das soluções habitacionais propostas, na justificação de suas formas de produção e na opacidade de seu estreito relacionamento com as lógicas económicas dominantes, logrando assim separar as pessoas do desenho do habitat residencial.
\end{abstract}

Palavras-chave: política de habitação, habitação social, habitação-mercancia, conhecimento técnico, habitar.

\section{Introducción}

En América Latina, desde la década de 1950 aproximadamente, y a propósito de la reflexión sobre los procesos de modernización y las condiciones necesarias para alcanzar el desarrollo, los discursos técnicos y la ciencia aplicada han adquirido progresivamente un rol gravitante en la producción de interpretaciones impulsoras de la acción política y se han configurado como insumos fundamentales para el diseño e implementación de políticas públicas (Garretón, 2014), autonomizándose en el campo burocrático de la administración del Estado e instituciones que lo influyen.

Uno de los ámbitos privilegiados en torno al que se ha articulado el saber técnico y el conocimiento aplicado es el de "las ne- 
cesidades y carencias de la población", impulsando "un sistema de intervenciones (...) aplicables más o menos universalmente con el objeto de llevar algunos bienes 'indispensables' a una población 'objetivo'" (Escobar, 2007, p. 45), naturalizando con ello lo que se entiende por necesidad y restando progresivamente de las potenciales soluciones a la población que supuestamente la padece.

En este marco, un elemento central ha sido la tematización de las necesidades habitacionales, cuyas particularidades radican en que son un asunto clave en el marco de las teorías de los mínimos sociales (Álvarez, 2005) que están en la base de muchas políticas sociales; en la continua tensión entre discursos técnicos constructivos y técnicos sociales, que encierra la configuración del hábitat residencial como espacio donde confluyen realidades físico-materiales y socioculturales (Fernández, 2001); y, finalmente, en que las formas que adquieren sus satisfactores tienen una gran influencia en la producción de configuraciones domésticas y en la configuración familiar (Ducci, 2007), por lo tanto, en las formas que adquiere la reproducción social.

Desde estas especificidades, las necesidades habitacionales, las poblaciones carenciadas y los satisfactores se construyen y aparecen como una realidad objetiva sobre la cual se erige el andamiaje de la política habitacional, naturalizando sus soluciones y justificando sus formas de producción, opacando su estrecha relación con las lógicas económicas hegemónicas y separando a las personas de la posibilidad de influir en la construcción de su hábitat.

En este marco, el presente artículo presenta una reflexión respecto de las especificidades del proceso de mercantilización de la vivienda social en Chile, analizando la concepción del hábitat que este ha implicado y el tratamiento de la vivienda y los espacios habitables como "objetos" separados de los "sujetos" (Salgado, 2014), desconociendo otros saberes y formas de satisfacción de necesidades residenciales. Asimismo, presenta una reflexión sobre el rol del conocimiento de expertos y las dicotomías que 
este contiene al descomponer la vivienda en dimensiones técnicas constructivas y dimensiones sociales, donde las primeras se presentan como hegemónicas.

Para ello se relevan las especificidades de la vivienda y su rol simbólico en el marco de la vida cotidiana y en su proceso de mercantilización; se sintetizan los principales hitos de la política habitacional chilena, analizando con mayor detención la política subsidiaria de las últimas décadas y la separación con el mundo de la vida cotidiana que ha implicado, amparada en dicotomías que movilizan ciertas formas que asume el proceso de diseño de las soluciones habitacionales. Finalmente, se realiza una reflexión sobre el rol de los discursos de expertos en la tecnificación de las necesidades y, con ello, la separación de los habitantes en el diseño del hábitat residencial; en esta línea, se destaca la necesidad de rescatar la vigencia de reflexiones en torno a la vivienda como proceso y el rol que tienen las ciencias sociales en ello.

\section{La vivienda y su rol simbólico}

El intento por entender y transformar el hábitat implica la comprensión del "habitar" desde un enfoque vivencial, asumiendo la concepción del espacio como emergente a partir de las prácticas de los sujetos en sus vidas cotidianas (Imilan, Jirón e Iturra, 2015). Desde esta perspectiva, "la experiencia del habitar se conforma a partir de raíces y rutas, (...), el espacio se experimenta y significa tanto en las relaciones fijas y residenciales, como en los viajes que se realizan" (Imilan et al., 2015, p. 88). Así, en la movilidad cotidiana de los trayectos, en la ruta de ida y también en el retorno a la habitación, a la casa, se desenvuelve el habitar como una práctica que, a decir de Heidegger: es "la manera en que somos en la tierra (...) [pues], ser humano significa habitar" (Heidegger, 1951, p. 2).

En el marco de las rutinas de la vida cotidiana, la vivienda, según Giannini (1987), como lugar al que se regresa siempre, como punto de partida y retorno, es fundamental como espacio 
de contención de la dispersión de la calle y la enajenación del trabajo, y como uno de los elementos estructurantes de lo cotidiano y de las prácticas del habitar.

Entendida como espacio acondicionado para la vida y escenario de la existencia privada, la vivienda, según Bourdieu (2010), es objeto de una serie de actividades y representaciones que podrían calificarse de "mitopoyéticas" (término tomado por Bourdieu de E. Cassire), es decir, que logran trasmutar el objeto en una realidad cargada de significaciones, otorgándole un halo sagrado al identificarse en lo que podríamos denominar como la encarnación de la familia, lo visible de sus particulares relaciones.

Al tratarse de un objeto material, observable, perdurable y vinculado a un proyecto de convivencia familiar, adquiere especificidades que la distinguen de otros elementos importantes en la reproducción de la vida, vinculados hoy principalmente a la presentación de servicios individuales. En este sentido, se trata de un objeto particular en la medida en que denota, más que cualquier otro bien, las características sociales de su habitante, su posición en el espacio social, dada por la estructura de capitales y trayectoria de vida (Bourdieu, 2010). Su rol simbólico está dado porque no solo designa al edificio, sino que también a sus habitantes como grupo; por tanto, es indisociable del hogar, de la idea de "proyecto familiar" y del refuerzo de los lazos de familia.

Por otro lado, la vivienda corresponde, para la mayor parte de los hogares, a la inversión económica más importante; por tanto, su rol simbólico se asocia a la valorización de la casa como elemento que dure para siempre, como "capital" familiar, heredable a futuras generaciones, no solo como patrimonio económico, sino también como manifestación viva del éxito y perdurabilidad del proyecto familiar.

De este modo, la vivienda puede ser entendida como el espacio físico en el que se enmarca la reproducción social más básica y cotidiana; según plantea Borja (2015), "la vivienda es algo más que la vivienda. Es el lugar donde convivir, reproducir la fuerza 
de trabajo y construir lazos afectivos. La vivienda es también una de las condiciones para acceder de facto a la ciudadanía" (p. 245). Sus bordes, su capacidad de contención y cobijo de un grupo humano influyen en la estructura que asume la familia como unidad reproductora, productora y de consumo, según el momento histórico que se observe; por lo tanto, es un elemento central en la vida doméstica y en la vida cotidiana. La forma que adquiera será determinante en las configuraciones familiares y, a su vez, la fuerza de las necesidades y de las labores reproductivas, los gustos y las costumbres, determinarán su forma y devenir. En este sentido, la vivienda, como un espacio de convivencia familiar, estructura y es estructurada por la vida cotidiana.

La manera en que se accede a ella, en función de las formas de satisfacción de necesidades determinadas por cada sociedad, en distintos momentos históricos, y la fuerza que adquiere en lo cotidiano, es determinante en su comprensión, ya sea como espacio privado que articula a sus habitantes con el entorno, como objeto de luchas y reivindicaciones sociales, como espacio autoconstruido colectivamente o como dispositivo de disciplinamiento y de atomización, en una forma de captura en el ámbito de lo privado, al funcionar, dirá Bourdieu (2010), como una trampa de diversas maneras:

[por ser el] lugar de fijación de todas las inversiones: las que están implicadas en el trabajo material y sicológico; (...) las que suscita a través del sentimiento de posesión, que determina una especie de domesticación de las aspiraciones y los proyectos, en lo sucesivo limitados a la frontera del umbral y encerrados en el orden de lo privado -en oposición a proyectos colectivos de la lucha política, por ejemplo, que siempre debían conquistarse contra la tentación del repliegue hacia el universo doméstico-; las que inspira al imponer un nuevo sistema de necesidades, inscripto en las exigencias que encierra a los ojos de quienes pretender estar a la altura de la idea que se hacen de ella (p. 211). 
Así, su forma de producción, determina, en buena medida, la vinculación que esta tengan con los habitantes; por lo tanto, denota la concepción del habitar y las prácticas asociadas a él en cada momento histórico.

\section{La vivienda como mercancía}

Considerando estas especificidades, la cuestión de la vivienda aparece hoy como un asunto fundamental a la hora de hablar de satisfacción de necesidades básicas, de dignidad y derechos sociales, incluso como derecho humano² (Oficina del Alto Comisionado para los Derechos Humanos, 2010). No obstante, adquiere la categoría de "problema", socialmente reconocido y susceptible de ser abordado desde aparatos que administran e intervienen el territorio, cuando la vivienda se erige como un objeto cultural (Fernández, 2001) con las características revisadas más arriba, es decir, como entidad con valores simbólicos y económicos que trascienden su dimensión evidente: la física material y funcional. Según el arquitecto y urbanista argentino Raúl Fernández Wagner (2001), en su análisis histórico de la reflexión y enseñanza de cuestiones relativas a la arquitectura y la vivienda social, este proceso puede situarse cuando la autoconstrucción pasa a ser una herramienta secundaria para proveerse de espacios residenciales, justamente en el momento en que

habitar la ciudad implicaba una nueva división del trabajo, y la vivienda -anteriormente autoconstruida de los sectores populares en el contexto rural- pasa a ser producida por especialistas y, por lo tanto, la única forma de acceder a ella es mediante la adquisición en el mercado inmobiliario urbano (Fernández, 2001, p. 41).

2 El derecho humano a una vivienda adecuada es definido por el Comité de las Naciones Unidas de Derechos Económicos, Sociales y Culturales como el derecho a un lugar donde vivir en seguridad, paz y dignidad (Oficina del Alto Comisionado para los Derechos Humanos, 2010). 
Este periodo coincide con la asociación de industrialización con urbanización, cuestión que impone un nuevo escenario por la escasez de viviendas para alojar a los nuevos trabajadores de la economía industrializada o en proceso de industrialización. A decir de Engels (1941), la época de la escasez de viviendas coincide "con el momento en que un país (...) sufre la transición de la manufactura y pequeña empresa a la gran industria" (p. 14). Así, dirá el autor, "la urgencia de viviendas es propia de la época capitalista, en la que la concentración de la población obrera en las grandes ciudades y la consiguiente despoblación de los campos plantea con caracteres nítidos el contraste ciudad-campo" (Engels, 1941, p. 9).

En esta trayectoria se vislumbran dos elementos relevantes: el proceso de mercantilización de la vivienda y la relación entre vivienda, acceso a la ciudad y acceso al mercado de trabajo urbano (Fernández, 2001).

La mercantilización se refiere a un proceso por el cual el valor de cambio de una vivienda prevalece por sobre su valor de uso, es decir, por sobre la capacidad de un determinado bien de satisfacer las necesidades humanas. Ello implica que, en términos generales, el proceso de satisfacción de necesidades habitacionales queda determinado por la conversión de la vivienda en una mercancía, en un objeto producido con miras al intercambio económico en un determinado mercado. En términos históricos, la mercantilización alude al paso de este satisfactor, a lo largo del tiempo, desde el nivel de la vida económica que Braudel (1984) llama "vida material" -en el cual ubica la autorreproducción y, por tanto, la autoconstrucción- al nivel que denomina del "capitalismo", definido por el operar de un número reducido de grandes empresas monopólicas o cuasi monopólicas que controlan determinadas industrias gracias a su poder económico y extraeconómico, y fundamentalmente gracias a sus vínculos con el Estado.

En este paulatino tránsito del mundo de la vida material a la economía capitalista, la vivienda se erigió como un objeto cultu- 
ral y foco del conocimiento de expertos y discursos técnicos, que buscan la generación de las lógicas de su producción y su comprensión como necesidad universal, y los satisfactores mínimos a los que debiera acceder toda la población. En este proceso histórico la técnica, dirá Lefebvre (1972, p. 20), reduce el habitar como actividad "a una realidad brutalmente material, a una función", ya no característica de quienes habitan sino que es propiedad de los lugares, dejando que la estructuración de lo cotidiano poco a poco dependa de aquellos que lo organizan y programan.

Así, para Lefebvre (1983, citado en Rodríguez, 2016), el habitar como práctica en la que se produce el espacio en búsqueda de valores de uso, de lugares para la vida, se va separando del construir y, a su vez, el construir, actividad central del habitar como productor de "lugares que cuidan", dirá Heidegger (1951), se va erigiendo como un oficio vacío al servicio de la planificación de la industria y el negocio de la construcción. De este modo, el proceso descrito decanta en una "producción (...) controlada por un constructor, promotor o desarrollador privado que invierte con un propósito lucrativo en la construcción de viviendas que se ofrecen en el mercado a demandantes solventes" (Ortiz, 2011, p. 19), por tanto, implica también que la vivienda-mercancía, mediante un vínculo contractual de arrendamiento y particularmente de propiedad, se erige como la única forma válida de satisfacer las necesidades habitacionales. Esta concepción de la vivienda como un producto implica la generación de un conjunto de instrumentos, como un sistema hipotecario, mecanismos de titulación y registro de la propiedad, garantías que respalden la recuperación de los créditos, sistemas de información sobre la oferta y sistemas de subsidios destinados a la adquisición de vivienda en el mercado para quienes no pueden acceder a ella por su propios medios (Ortiz, 2011).

Estos elementos, poco a poco se volverán una constante en el marco del sistema de acumulación capitalista y, más allá de los modelos de desarrollo vigente, constituirán a la vivienda, y en particular a la "vivienda de interés social", como la cristalización 
del derecho a alojamiento (Fernández, 2001), subsumiendo en esta categoría una economía particular movilizada por el control del suelo urbano, la necesidad de contener potenciales conflictos, generar procesos de integración social e introducir la propiedad de la casa como imagen encarnada de la posibilidad de ascenso social: como un principio de diferenciación entre la ciudad formal y la ciudad informal-marginal-precaria; entre estabilidad familiar e inestabilidad; entre éxito y fracaso.

A partir del proceso de mercantilización y el tránsito del nivel material de la economía al nivel del capitalismo, la vivienda va adquiriendo significados construidos socialmente, desde la compleja interacción entre su dimensión de satisfactor de necesidades consideradas como básicas, los discursos promulgados desde los agentes estatales e inmobiliarios y los sentidos que le otorgan las personas, instalándose las acciones y prácticas en torno a la resolución de problemas del habitar en el marco de las tipicidades de la vida cotidiana.

$\mathrm{Al}$ respecto, un elemento central de la construcción sociohistórica del artefacto cultural vivienda-mercancía adquirida en propiedad, es que aparece como "dotado de legalidad propia" (Toledo, 2012, p. 272), es decir, aparece como la forma obvia y natural de satisfacer las necesidades residenciales.

En este marco de tipificaciones para la resolución de problemas y satisfacción de necesidades habitacionales, Bourdieu (2010) señala que el mercado de casas es el producto de una doble construcción social, en el cual el Estado juega un rol clave: construyendo demanda a través de la producción de disposiciones individuales a la propiedad y también asignando los recursos. Ello quiere decir que el mercado de vivienda, entendido como campo económico, "está habitado más que cualquier otro por el Estado, que contribuye en todo momento a su existencia y persistencia, pero también a la estructura de relaciones de fuerza que lo caracteriza. Cosa que hace, especialmente, por medio de las diferentes políticas" (Bourdieu, 2010, p. 25), ya sea mediante el apoyo otor- 
gado a los particulares y, fundamentalmente, por la regulación del suelo urbano. Este último elemento mencionado por el autor es central, ya que la particularidad del suelo está dada porque su valorización, y por tanto sus precios, no provienen principalmente de la fuerza de trabajo invertida en él ni de sus características intrínsecas, sino que de elementos externos que pueden ser atribuidos, la mayor parte de las veces, a las acciones del sector público -básicamente a la inversión en infraestructura, equipamientos, servicios- y a la definición de una normativa urbana, es decir, lo que es posible hacer en un determinado lugar, lo cual va determinando las diferencias entre las localizaciones, sus "amenidades" $y$, con ello, sus precios (Smolka \& Ambroski, 2003).

En resumen, dirá Bourdieu (2010), en el mercado de las casas individuales el Estado hace una contribución central:

construcción de la demanda, a través de la producción de las disposiciones individuales y, más precisamente, de los sistemas de preferencias individuales -en materia de propiedad (...) - y también por medio de la asignación de los recursos necesarios, es decir, las ayudas estatales a la construcción o la vivienda definidas por leyes y reglamentos cuya génesis es igualmente posible describir; construcción de la oferta, a través de la política del Estado (p. 32).

\section{Las políticas estatales de vivienda en Chile: una breve mirada histórica al proceso de mercantilización}

En el caso de Chile, una parte central de la concepción de la vivienda como un producto y su paso al nivel económico del capitalismo está íntimamente relacionada con la historia de la política habitacional y el actuar del Estado durante el siglo XX. Las acciones que este ha emprendido en la materia se relacionan directamente con la forma en que adquiere los modelos de desarrollo, es decir, 
con una visión y una práctica que articula una dimensión económica, entendida como el conjunto de relaciones entre factores de producción -lo cual lleva a patrones diferentes de generación de bienes y servicios, empleo e inversión-, y una de cambio social, que asigna roles al Estado y a los agentes económicos locales (Garretón, Cavarrozi, Cleaves, Gereffi \& Hartlyn, 2004).

No obstante, predomina una forma de análisis de la acción estatal que tiende a disociar las políticas sociales de los procesos de mercantilización de bienes y servicios considerados como esenciales, concibiéndolos como asuntos separados y estableciendo una división entre mercado y Estado (Ruiz, 2013). Esta perspectiva "deshistoriza" el rol del Estado y la especificidad que este adquiere en América Latina como un actor decisivo en la instauración del capitalismo (Faletto, 1989), en el impulso de sus grandes transformaciones, así como en la formación de ciertos nichos de mercado particulares, asociados a la satisfacción de necesidades básicas para los sectores más empobrecidos de la población.

En este marco, el caso chileno destaca por ser ilustrativo de la vinculación orgánica entre Estado y procesos de mercantilización, en particular de aquellas cuestiones que aseguran las condiciones de reproducción de la población (Ruiz, 2013), como es la vivienda.

Al respecto, es importante considerar algunos elementos históricos relativos a la institucionalidad pública preocupada de la cuestión habitacional en Chile y sus transformaciones, como datos contextuales que permiten explicar la especificidad de los procesos de mercantilización de la vivienda, en particular de la vivienda de interés social. En esta trayectoria destacan algunos hitos que muestran cómo el radio de acción de la política pública ha ido en constante aumento y cómo ello se vincula con nuevas lógicas para la provisión de viviendas asociadas a la producción mercantil, y nuevos discursos técnicos que, paulatinamente, han generado un quiebre entre los procesos constructivos y las prácticas de habitar. 
Según Castillo e Hidalgo (2007), Chile fue uno de los primeros países de América Latina en contar con una legislación habitacional: la Ley de Habitaciones Obreras ${ }^{3}$, promulgada en 1906, la cual, con una marcada orientación "higienista", constituye el punto de partida de una progresiva institucionalización de los organismos vinculados al Estado preocupados por la cuestión de la vivienda.

Avanzadas las primeras décadas del siglo XX, las transformaciones en las necesidades residenciales y en la institucionalidad preocupada de ello están marcadas por el declive del patrón económico exportador, predominante en el siglo XIX, articulado en torno a la producción de materias primas y orientado principalmente al mercado externo. Este declive comienza a partir de la década de 1920 (Moulian, 1997; Garretón, 2014) y tiene como contexto internacional la Primera Guerra Mundial y la crisis del capitalismo, en la década de 1930, que crea las condiciones para que se impulse, en forma sostenida, "una trasformación de la estructura productiva chilena orientada a lograr la sustitución de importaciones y cubrir parcialmente la demanda interna" (Ruiz y Boccardo, 2014, p. 15).

El impulso al desarrollo industrial conducido directamente por el Estado significó que las ciudades se constituyeran como polos migratorios, atrayendo población bajo la ilusión de mejores condiciones de vida para las familias. En términos de la habitación popular de las masas de migrantes, el historiador De Ramón (2006) señala que:

(...) los conventillos, cités y casas alquiladas por habitaciones separadas fueron incapaces de albergar a toda la masa migrante que el desarrollo industrial ya sugerido fue capaz de atraer (...) con lo cual la única posibilidad de acción por parte de los sectores populares fue la au-

Esta Ley da pie a la formación de los Consejos de Habitaciones Obreras (1906), con facultad de construcción directa para arriendo, pero centrado fundamentalmente en la higienización-demolición de viviendas existentes de mala calidad (Hidalgo, 2006; MINVU, 2007). 
toconstrucción con materiales de desecho y en terrenos que no les pertenecían (p. 288).

De esta manera, el proceso industrializador trajo como resultado una redefinición demográfica, social y morfológica de las ciudades, en la cual la informalidad urbana y los asentamientos precarios otorgaron relevancia crítica a la cuestión habitacional como elemento clave en la reproducción social, y al Estado como garante de las condiciones físico-poblacionales para el desarrollo productivo y posibilitador de la reproducción de la fuerza de trabajo (Raposo, 2001).

En este marco, surgen distintas iniciativas desde el Estado que buscan, progresivamente, convertir a la dotación de viviendas en un elemento relevante para "el desarrollo del capitalismo 'privado' a través de la provisión de servicios públicos y sociales" (Raposo, 2001, p. 5). Destaca la Caja de Habitación Popular, creada en 1936 para la construcción directa de viviendas, para arrendar o vender al largo plazo, otorgar concesiones de subsidio y garantías a quienes invirtieran capitales en viviendas económicas, y generar disposiciones que obligaban a las empresas a destinar un porcentaje de sus utilidades a la construcción de barrios obreros (MINVU, 2007; Valenzuela, 2007).

Las iniciativas de la Caja de Habitación Popular fueron insuficientes para albergar a la nueva población urbana, en la medida que se concentraron en la generación de incentivos para la construcción de viviendas para obreros, por lo que excluían a quienes no estaban insertos en la estructura productiva.

En este escenario, en 1953 se crea la Corporación de la Vivienda, CORVI, con labores de construcción directa para las cajas de trabajadores, la generación de incentivos tributarios para constructoras y compradores, y el apoyo a la autoconstrucción con una urbanización mínima (Raposo, 2001; MINVU, 2007). En este marco, en el gobierno de Jorge Alessandri Rodríguez (1958-1964) se promulga el $\mathrm{DFL} \mathrm{N}^{\circ} 2$, vigente sin modificaciones hasta 2010, también conocido como Ley del Plan Habitacional, destinado a 
aumentar la producción de viviendas, con el objetivo explícito de incorporar activamente al sector privado ${ }^{4}$.

La labor de la CORVI, aunque de mayor cobertura que la Caja de Habitación Popular, también se concentró en la construcción para trabajadores organizados en torno a las cajas. En este sentido, la vivienda "económica" de este periodo se constituye como una vivienda eminentemente obrera y ejerce un rol central en la formación de una incipiente industria de la construcción de casas.

En 1965 se crea la entidad gubernamental que hasta hoy diseña e implementa las políticas urbanas y habitacionales: el Ministerio de Vivienda y Urbanismo (en adelante MINVU). El origen de esta institución responde al contexto internacional de la "Alianza para el Progreso", cooperación entre Estados Unidos y los países latinoamericanos para la puesta en marcha de políticas de desarrollo nacional y, particularmente, para alejar potenciales procesos revolucionarios que cuestionaran la hegemonía vigente (Equipo Interdisciplinario de Investigación y Enseñanza del Planeamiento y del Desarrollo Urbano, 2006).

Los planes habitacionales debían responder a reivindicaciones urgentes, acrecentar la integración institucional de la enorme población marginal de las ciudades y fomentar la actividad económica (Espinoza, 1988), fortaleciendo a un sector especial de la economía: la industria de la construcción ${ }^{5}$.

\footnotetext{
4 El Decreto con Fuerza de Ley Número 2, del 31 de julio de 1959, buscaba promover la construcción masiva de viviendas mediante la aplicación de franquicias tributarias, tanto para las empresas constructoras como para los compradores.

5 Cabe destacar la influencia de la política estadounidense de incentivos tributarios para la construcción y adquisición de viviendas, diseñadas desde 1947, que fomentaron como algo central en el "sueño americano" la vivienda en propiedad. Según señala Harvey (2013), la propiedad de la vivienda es un valor cultural en Estados Unidos, promovido y subvencionado por la política pública como una forma de activar la economía poscrisis de 1930 y Segunda Guerra Mundial, y como una forma de evitar huelgas y emplazamientos de la población al Estado mediante la deuda inmobiliaria (según el autor, esto se ha reconocido explícitamente en informes del Banco Mundial).
} 
En el contexto de la creación del MINVU, una de las principales herramientas fue el Plan de Ahorro Popular, que contemplaba cinco líneas de acción, desde la provisión de un sitio demarcado, sin urbanización ("Operación Tiza"), hasta un departamento, en el que cada línea correspondía a la capacidad de pago de las familias (MINVU, 2007).

De este modo el Estado, progresivamente, adquiere una función "reproductora, legitimadora y reguladora del sistema económico social capitalista" (Raposo, 2001, p. 5), creando las condiciones para el desarrollo de nichos de acumulación privada. En el caso del ámbito de la construcción, otorga las condiciones para la gestación de un sector que se enfoca en la producción de viviendas para las capas medias y ciertos sectores obreros.

En lo que respecta a los sectores marginales, los primeros momentos de la gestión del MINVU despiertan grandes expectativas, que se ven aumentadas con la llegada al gobierno de la Unidad Popular (1970) y el Plan de Emergencia Habitacional, que pretende ampliar los programas de vivienda a los sectores marginados, incorporando a los pobladores en la gestión de los proyectos. Sin embargo, conforme avanza la gestión gubernamental, las expectativas se transforman en impaciencia y las organizaciones comunitarias, estimuladas por el Estado, dan lugar a una demanda que las políticas públicas no pueden absorber.

Los esfuerzos de contención de las demandas sociales no son suficientes y el periodo exhibe una radicalización sociopolítica creciente y un cuestionamiento al orden socioeconómico. En este marco, las fuerzas conservadoras interrumpen el gobierno de la Unidad Popular, en 1973, con un golpe de Estado encabezado por los militares, que da pie a una dictadura militar que desmoviliza por la fuerza a la población y cuyos términos de constitución en un régimen se transforma en un "campo de disputa entre quienes apoyan un desarrollo nacional menos popular y otros que alientan la transformación radical del patrón de acumulación capitalista" (Ruiz y Boccardo, 2014 p. 20). Es este último escenario el 
que termina proyectándose, impulsado por jóvenes economistas gremialistas de la Universidad Católica.

De este modo, en el marco de la dictadura militar (1973 a 1990) se imponen las bases para la nueva fase neoliberal del capitalismo en Chile.

Siguiendo los planteamientos de Harvey (2011),

el neoliberalismo es, ante todo, una teoría de prácticas político-económicas que afirma que la mejor manera de promover el bienestar del ser humano, consiste en no restringir el libre desarrollo de las capacidades y de las libertades empresariales del individuo, dentro de un marco institucional caracterizado por derechos de propiedad privada, fuertes mercados libres y libertad de comercio. El papel del Estado es crear y preservar el marco institucional apropiado para el desarrollo de estas prácticas (p. 8).

Sin embargo, pese a su declarada defensa del "libre mercado", el nuevo modelo no solo fue impuesto a la fuerza en el marco de enormes restricciones a las libertades colectivas e individuales, sino que además el Estado, más que un ente regulador de las imperfecciones del mercado, pasó a fomentar y a ser el garante de la generación de monopolios y oligopolios en diversas áreas de la economía, que perpetuaron una competencia imperfecta.

Las reformas estructurales para la implementación de esta doctrina vinculan los ejes del desarrollo nacional a las fuerzas transnacionales del mercado en sus dimensiones productiva, comercial y sobre todo financiera, adoptando un modelo de desarrollo fundado en la integración del país a los mercados internacionales, mediante la exportación de los productos, casi siempre primarios, en los que se tuviera ventajas comparativas.

Lejos de lo que dicta la doctrina neoliberal, la acción estatal posibilita la formación de nuevos grupos económicos, reorganizando las condiciones de acumulación al subvencionar la "com- 
pra" de las empresas estatales y entregar a ciertos grupos financieros el control del sistema de pensiones, los servicios básicos, el sistema de salud y el sistema educacional (Ruiz y Boccardo, 2014). En este sentido, la generación de "nuevas fortunas", lejos de forjarse al alero de la competencia del libre mercado, imagen que se ha intentado propagar para naturalizar el orden social, es dependiente de la acción estatal.

De este modo, la transformación no implicaría una desregulación sistemática que transfiere funciones del Estado asociadas a la reproducción de la vida al mercado, sino que el Estado crea los nuevos nichos en una suerte de acumulación originaria y, a la vez, con un creciente rol subsidiario a la demanda, promulgando la figura del subsidio en las políticas públicas como una ayuda directa a "los verdaderos pobres", mediante la focalización del gasto público en programas sociales enfocados en la extrema pobreza (Ruiz, 2013).

En este contexto, en la primera mitad de la década de 1980 surge un modelo de política habitacional "centrada en el instrumento de subsidio a la demanda y su complemento con el ahorro y crédito" (MINVU, 2007, p. 184). El subsidio habitacional fue pensado como un mecanismo que favorece la instalación de un sistema de producción masiva que consistiría en un sistema de ayuda directa al beneficiario. Con ello, la empresa privada, que usualmente había desarrollado sus proyectos para un mercado de altos y medianos ingresos con capacidad de endeudamiento, amplía su nicho hacia la construcción de viviendas económicas para sectores sin capacidad de endeudamiento.

En este periodo surge, normativamente, la noción de "vivienda social", que será definida técnicamente como una solución mínima estandarizada que facilita la producción masiva y la generación de economías de escala ${ }^{6}$. 
Un elemento central que favoreció la construcción de la vivienda social y definió la forma que asumió la urbanización neoliberal fue la Política Nacional de Desarrollo Urbano de 1979 (D.S. N 420 de Vivienda y Urbanismo, de 1979) que cambió la visión de la ordenación territorial privándola de una imagen objetivo, es decir, de una jerarquización normativa vinculada a formas de uso del territorio y actividades, movimientos cotidianos de la población y redes disponibles y proyectadas de infraestructura (MINVU, 2014). Esta política "liberó los límites urbanos y otorgó al mercado la asignación de los usos del suelo sin intervención estatal, quedando el uso del suelo definido por su mayor rentabilidad" (Rodríguez e Icaza, 1993, p. 3). Uno de sus principios rectores era que el suelo urbano no era un bien escaso, permitiendo con ello que el crecimiento urbano marchase acorde con las tendencias del mercado. A esta política le sucedió una "Ajustada", de 1985, buscando mitigar el impacto de la anterior en relación con el rol del Estado en las regulaciones mínimas sobre el uso de suelo, la cual fue derogada en 2000, debido a las contradicciones con otras reglamentaciones dictadas por el MINVU7.

Entonces, en este periodo se generan las bases para una política habitacional cuyos fundamentos se mantienen hasta hoy y que, a diferencia de algunos programas de décadas anteriores, se basa en un mercado de viviendas terminadas y estandarizadas, contemplando escasamente las tipologías flexibles que permitieran la participación del usuario y la autoconstrucción directa. De este modo, el Estado "abandona labores de financiamiento y construcción de viviendas permanentes, para concentrarse en

Viviendas Económicas (referido al artículo $1^{\circ}$ del Decreto con Fuerza de Ley $\mathrm{N}^{\circ} 2$, de 1959), se entenderá como vivienda social aquella "Vivienda económica de carácter definitivo destinada a resolver los problemas de la marginalidad habitacional, financiada con recursos públicos o privados, cuyo valor de tasación no sea superior a 400 UF y cuyas características técnicas y de urbanización se ajusten a las normas generales de este reglamento" (MINVU, 2014, p. 322).

En 2013 se promulgó una Nueva Política Nacional de Desarrollo Urbano (D.S. $\mathrm{N}^{\circ} 78$ de Vivienda y Urbanismo, de 2013), de cuyos planteamientos aún no se desprenden herramientas concretas. 
el subsidio habitacional y las viviendas sociales" (MINVU, 2007, p. 184), apoyando a las familias de menores ingresos en la compra de viviendas nuevas, dejando las labores constructivas al sector privado y asegurando, con esto, parte de la reproducción de la vida cotidiana.

Con el retorno a la democracia, en 1990, aumenta el presupuesto destinado al sector vivienda y con ello la cobertura de la entrega de subsidios para la compra de una vivienda en propiedad, alcanzando un ritmo de construcción de viviendas sociales inédito para América Latina, de 96.000 soluciones anuales (MINVU, 2007), lo que implica que entre 1990 y 1996 el déficit habitacional disminuyera en un $42 \%{ }^{8}$.

De este modo, se continúa con la política subsidiaria focalizada en los quintiles de ingreso más bajos, la cual, con el paso del tiempo, elimina el componente crediticio, introduce fórmulas de ajustes para mejorar la calidad y tamaño de las viviendas entregadas, y limita las exigencias financieras a un porcentaje mínimo de ahorro (actualmente 10 unidades de fomento).

Este modelo se constituye como una forma de producción controlada por agentes privados, pionera en América Latina (Rodríguez \& Sugranys, 2004; Ducci, 2007), y reconocida como reconocida como exitosa por su enorme cobertura y una inédita activación del sector de la construcción con financiamiento estatal, llegando incluso a que, en el periodo que va desde 1990 a 2003, cerca del 75\% de las viviendas construidas haya contado con financiamiento público (MINVU, 2007), y hasta 2015, según la última información estadística disponible, cerca del $64 \%$ de las familias chilenas sea propietaria de la vivienda que habita (MIDEPLAN, 2016) ", lo que le ha valido incluso "su exportación"

\footnotetext{
Calculado sobre la base de los resultados de la Encuesta de Caracterización Socioeconómica del año 1990 y 1996, CASEN, 1990, 1996. Recuperado en julio de 2012 de http:/ / observatorio.ministeriodesarrollosocial.gob.cl/casen_est_pobreza.php

9 El $20 \%$ es arrendatario y el $16 \%$ se encuentra en condición irregular de propiedad, en viviendas cedidas $u$ otras situaciones, sin existir grandes diferencias
} 
como buena práctica para el diseño de políticas públicas en otras latitudes (Rodríguez \& Sugranys, 2004; Ducci, 2007).

Discursivamente, en un primer momento de este modelo diseñado en dictadura la vivienda se situó en el marco de la sustracción de muchas responsabilidades estatales de la "política abierta", presentándolas como parte de problemáticas técnicas apolíticas y excluyendo del debate a fuerzas sociales (Ruiz y Boccardo, 2014), a los habitantes. En este sentido, el sistema político se autonomiza de sectores sociales distintos del empresarial, por lo que su capacidad representativa se debilita y "se reduce a administrar los consensos impuestos" (Ruiz y Boccardo, 2014, p. 29), difundiendo la imagen de lo "mal que se hizo en el pasado" por llevar "lo social" a "la política", lo que conduce a la aparente "tecnificación" de las decisiones políticas, en la separación de los problemas de quienes los experimentan.

Así, en dictadura, la vivienda aparece primeramente como una forma de satisfacer las necesidades más urgentes de los "verdaderos pobres", compensando los desalojos forzados masivos -producto de las erradicaciones de campamentos y asentamientos informales- con la propiedad de la casa y estableciendo un principio de diferenciación entre lo que acusa como un sector privilegiado - por estar vinculado a la presión sindical y política- y los marginales (Ruiz, 2013), para quienes había estado vedado el acceso a la vivienda formal.

Posteriormente, en democracia, con foco en las familias allegadas, se masifica el acceso a la casa propia y se estimula la alta valoración de la vida doméstica y la poca involucración en el proceso colectivo de creación de barrios, a partir de los sistemas individuales de postulación a un subsidio en el que las familias compiten entre sí y, cuando mucho, a partir de comités de viviendas con poca injerencia en los proyectos habitacionales.

en el peso relativo de la propiedad entre los distintos quintiles de ingreso, Encuesta de Caracterización Socioeconómica del año 2013, CASEN, 2013. 


\section{Estandarización e inflexibilidad: lo técnico y lo social como dicotomía}

En 2001 se implementa una nueva política habitacional, traducida en el programa Fondo Solidario de Vivienda, que asume que todos los grupos vulnerables son sujetos de derecho para la obtención de una solución habitacional, con independencia de las características y la especificidad de cada uno de ellos.

El Fondo Solidario de Vivienda (2001 a 2012) y su sucesor, el Fondo Solidario de Elección de Vivienda (vigente hasta hoy) operan como un fondo concursable de subsidios habitacionales para la gestión y compra de una vivienda. En este marco, el Estado externaliza el apoyo para que el subsidio se materialice en instituciones denominadas "entidades patrocinantes", quienes deben preocuparse de gestionar la oferta de viviendas para la ejecución del subsidio, apoyando la organización de las familias para los procesos de postulación colectiva a los programas habitacionales. Cabe destacar que estas entidades patrocinantes deben realizar una asistencia para la gestión del suelo y también una asistencia "social", plasmada principalmente en el denominado "Plan de Habilitación Social", que corresponde a una serie de actividades más o menos estandarizadas que buscan apoyar a las familias en el proceso de instalación en la casa nueva, "habilitarlas" para la vida en la vivienda definitiva, promoviendo cierto tipo de prácticas en el uso del espacio y evitando otras.

En este marco, la participación de los habitantes en el diseño de su vivienda ha sido concebida como un proceso en el cual los pobladores son "convocados" a intervenir en el contexto de un plan de acciones preconcebidas, que buscan principalmente informar sobre las posibilidades de colaboración enmarcadas en los sustentos técnico-económicos ("científicos") que amparan el devenir de los proyectos. Esta política entiende al territorio como externo a los sujetos, negando la posibilidad real de habitar y reduciendo su tratamiento a la técnica de la construcción (Salgado, 2014), desconociendo que el hábitat residencial es: 
el resultado de un proceso en permanente conformación de lugares en distintas escalas referidas al territorio, que se distinguen por una forma particular de apropiación, dada por un vínculo cotidiano con unidades de experiencias singulares, potenciando relaciones de identidad y pertenencia, a partir de lo cual el habitante lo interviene y configura (Caquimbo, 2009, p. 12).

En muchos casos, entonces, el cumplimiento del promovido imaginario del "sueño de la casa propia" y la consecución de un espacio para albergar a las familias resulta en paralelo a la desintegración de comunidades generadas en las situaciones residenciales previas, como ocurre por ejemplo en los asentamientos informales, comúnmente denominados en Chile como "campamentos".

En estos contextos, es posible evidenciar el quiebre de redes de subsistencia y estrategias de sobrevivencia, en particular cuando la intervención de la política pública implica relocalizar a las familias de manera dispersa en otros territorios, y lo que se obtiene es una vivienda estandarizada, incapaz de albergar las actividades productivas vinculadas directamente a la disponibilidad de espacio físico en las viviendas autoconstruidas (Rivas, 2013). Se genera entonces un quiebre en la vida cotidiana de las personas, un quiebre en su forma de satisfacer las necesidades materiales y con el acervo de conocimientos que tienen para enfrentarlas.

Por otro lado, en el caso de familias cuya condición previa era el allegamiento, la desintegración social estaría dada por la pérdida de las estructuras sociales tradicionales, basadas en la familia extensa (Ducci, 2007). Al respecto, Ducci (2007) señala que la política habitacional genera un diseño residencial basado en una "familia tipo", a lo sumo de cuatro personas, fomentando con ello la imagen de una "verdadera familia moderna" (p. 119), lo cual estimula las divisiones de núcleos familiares en la medida en que constituyen nuevas unidades de demanda habitacional. Así, la familia extensa, que había sido la base para la organización económica en sectores populares, tiende a desaparecer. 
Una tercera arista de la fragmentación, vinculada a la forma que asume la producción de viviendas sociales, corresponde al quiebre con la ciudad, por efecto de nuevas formas de territorialización de la pobreza, marcadas por la segregación residencial, como resultado de un modelo de urbanización que responde al patrón general de la economía, en el que priman los agentes dedicados a la captura de ganancias de capital antes que a la generación de ganancias de productividad. La irrupción de este esquema en el campo de provisión de viviendas implica una inversión inmobiliaria que rentabiliza mayormente a partir de plusvalías de suelo (French-Davis, López y Arriagada, 2013); por tanto, las decisiones relativas a dónde y cuándo se producen viviendas sociales dependerán de las ganancias esperadas en ciclos cortos de un año o menos, que progresivamente van desplazando a la vivienda económica a la periferia de la ciudad.

Desde el punto de vista de las características de la vivienda, por otra parte, su estandarización no admite ningún tipo de progresividad: son difícilmente adaptables a las necesidades de la familia, que son móviles y cambian a lo largo del ciclo de vida. No obstante, los hogares buscan fórmulas para modificar su hábitat, realizando ampliaciones autoconstruidas, ocupando espacios de manera informal para dar solución a sus necesidades de espacio, pero también para albergar actividades productivas y tener un mayor control de los hijos pequeños (Muñoz, 2011). Estas soluciones no solo se caracterizan por su precariedad, sino que también porque únicamente son posibles ocupando los escasos espacios comunes, pasillos, veredas, estacionamientos, transformándose muchas veces en fuente de conflicto entre los vecinos. En este sentido es que se afirma que la pobreza actual se caracteriza por estar marcada por los problemas de los "con techo" (Rodríguez y Suranyes, 2004).

Por tanto, las políticas de vivienda, además de fomentar determinadas predisposiciones, generan un quiebre con la vida cotidiana, con las necesidades materiales de las personas y también con su acervo de conocimientos para enfrentarlas, 
constituyéndose sobre la base de lo que el portugués De Soussa (2009) denominará "injusticia cognitiva", refiriéndose con ello a la exclusión de los saberes no amparados en los procedimientos de la ciencia occidental y subyugados por prácticas de colonización vinculadas al avance de los procesos de mercantilización y el capitalismo.

De este modo, la forma actual que adquiere la vivienda social se ampara en un "epistemicidio" (De Soussa, 2009) que omite las prácticas de habitar y el conocimiento que tienen las personas de sus propias necesidades, realizando diagnósticos basados en las carencias residenciales evaluadas desde estándares universales, separando el objeto "vivienda" de sus reales usos y marginando a sus habitantes bajo el amparo de un saber técnico tributario de un enfoque arraigado en la tradición positivista.

Según Fernández (2001), en efecto, las disciplinas asociadas al diseño y a la construcción de la vivienda social, como la arquitectura y la ingeniería, siguen siendo tributarias de lo que denomina "etapa profesionalista", marcada por lo que en la década de 1920 se entendió como el estudio científico de la vivienda, centrada fundamentalmente en la descomposición de las funciones mínimas del "habitar" al interior de la vivienda, para reorganizarlas buscando una mayor eficiencia en el desempeño de funciones domésticas consideradas como básicas en un determinado contexto (alimentarse, asearse, cocinar, etc.). De este modo, la denominada "máquina de habitar" "otorgaría mayor productividad a un sistema centralizado y masivo de provisión de viviendas" (Fernández, 2001, p. 41) a partir de la elaboración de estándares.

La técnica derivada de un enfoque mecanicista en la construcción del hábitat se autodefine como diferente de aquellas que derivan de las ciencias sociales, concibiéndose como más cercana al mundo de lo físico-natural.

En este contexto, los equipos profesionales que ejecutan los programas habitacionales se dividen en "técnicos" y "sociales" y se entiende por competencia de estos últimos la determinación 
de niveles de vulnerabilidad de las familias (desde instrumentos previamente diseñados y estandarizados), el acompañamiento en el proceso burocrático de adquisición de un subsidio y la aplicación de la "habilitación social", como preparación de las familias para la vida en una casa nueva, la adaptación de sus actividades cotidianas al espacio diseñado y definido por "la técnica", la que no les permitirá mantener prácticas de subsistencia fundamentales, como los pequeños cultivos, el acopio de material de trabajo, la tenencia de caballos y carretones, entre otros. Este rol de las disciplinas asociadas a "lo social" queda de manifiesto en las palabras de un joven habitante de un campamento de Viña del Mar, enterado de la información entregada en el marco de las actividades del Plan de Habilitación Social:

Yo tengo ocho perros, un conejo, un gato y un caballo (...) no sé qué vamos a hacer con los perros cuando nos vayamos a la casa nueva (...), no se va a poder trabajar, van a tener que vender los carretones y los caballos (...) acá la mayoría de las casas son todas grandes, las familias se han agrandado para atrás (Rivas, 2013, p. 97).

De este modo, la intervención social, entendida como un proceso orientado a producir un cambio en situaciones consideradas problemáticas (Matus, 2001), queda subordinada a los procesos de consecución de la vivienda y a la adaptación de las familias a éstas, desentendiéndose de la comprensión de las prácticas de habitar y de las posibilidades de influir desde allí en el diseño. La "dimensión social", entonces, queda reducida a instancias limitadas de participación ciudadana, para "opinar" de planes diseñados bajo criterios de expertos de la dimensión "técnica".

Las consecuencias negativas de esta dicotomía imponen la necesidad de identificar mejor los requerimientos habitacionales actuales sobre la base de la real observación de las formas de habitar, relevando los procesos de producción social del hábitat y superando las dicotomías ancladas en la política pública. 


\section{Reflexiones finales: la vivienda como proceso}

El proceso de mercantilización de la vivienda en Chile, particularmente de la vivienda de interés social, está profundamente marcado por el rol central del Estado en el marco de las transformaciones del capitalismo, particularmente en el giro neoliberal ocurrido durante la década de 1980.

Esta estrecha relación entre Estado y capitalismo cobra especial relevancia en el análisis de las políticas sociales, particularmente de las políticas de vivienda, por el rol simbólico que esta adquiere en cuanto objeto perdurable y estrechamente relacionado con los proyectos familiares, así como también por su peso en la satisfacción de las necesidades consideradas básicas.

El paso de la política habitacional centrada en la vivienda obrera a la vivienda social subsidiada permite observar cómo el giro neoliberal no representa una retirada del Estado, sino que un proceso de facilitación de la mercantilización de la habitación económica, en el marco de una privatización generalizada de las condiciones de reproducción social.

En este escenario, los discursos de expertos, entendidos como sinónimos de saberes técnicos asociados a las disciplinas enfocadas en la dimensión física y material del hábitat, cobran cada vez más fuerza, dada la posibilidad que otorgan de estandarizar los procesos, definiendo lo que entienden por "necesidad habitacional" y, con ello, generando las lógicas que justifican la producción de nuevas unidades de vivienda.

De este modo, siguiendo a Escobar, los discursos denominados "técnicos", que se instalan en el quehacer profesional del diseño de las políticas públicas habitacionales,

proporcionan las categorías con las cuales los "hechos" pueden ser nombrados y analizados, y cumplen por ello un rol importante en la constitución de los fenómenos que la organización conoce y describe. Los hechos son presentados en formas estandarizadas para que puedan ser repetidos en caso necesario (Escobar, 2007, p. 168). 
Desde estos discursos se va excluyendo el sentido común en las prácticas de habitar, contenido en los procesos históricos de producción social del hábitat. Superar estas exclusiones no solo implica enmarcarse en un sistema de producción de la vivienda totalmente diferente, sino que significa lo que De Soussa (2009) denomina una "nueva actitud epistemológica" que se deje penetrar por los saberes construidos históricamente en los territorios. Al mismo tiempo, se requiere superar la dicotomía entre la técnica constructiva y la intervención social, lo que depende del fortalecimiento de la transdisciplina en relación con los procesos de diseño urbano y habitacional.

Desde este nuevo horizonte epistemológico se requiere iniciar una reflexión acerca de los estándares de la vivienda y la metodología para su diseño.

Para ello, parece pertinente rescatar la vigencia de discusiones respecto de la vivienda social como proceso que, en términos de Haramoto (2013), implica concebir al diseño como "la fase del proceso habitacional que consiste en la conformación y configuración de alojamiento para la vida humana, tanto individual, familiar y vecinal como comunitaria, dentro de un territorio" (p. 242).

Las exigencias de una vivienda social como producto-mercancía, en palabras de Haramoto (2013), apuntan a caracterizarla solamente según sus atributos y no según sus usos, sin considerar la posibilidad de adaptación de acuerdo con los modos de vida de las familias y sus propias transformaciones. En cambio, concebir el diseño de la vivienda social como proceso, significa entender la necesidad de un posterior desarrollo y cambio a medida que se habita, permitiendo "incorporar recursos extraeconómicos, como la autoconstrucción, el apoyo solidario, materiales reciclados, etc." (Romero y Mesías, 1999, p. 30).

Esta visión implica desvincular la vivienda de la noción de "mercancía", sacarla del circuito de los valores de cambio y centrarse en su valor de uso. Ello significa dotar de un nuevo significado a la vivienda social financiada por el Estado, manteniendo 
su condición de estar destinada para la población vulnerable y, a la vez, reconocer su función social de espacio para la vida. De este modo, se requiere considerar modelos alternativos al predominante hoy en la política habitacional, buscando esquemas que permitan incorporar esta visión del alojamiento humano como proceso y su énfasis en el "carácter dinámico y evolutivo, incluyendo etapas de prospección y planificación, diseño, construcción, transferencia, alojamiento, administración (mantención y mejoramiento)" (Haramoto, 2013, p. 243).

La vivienda así concebida, implica que su propio diseño necesita un nuevo rol de los profesionales comúnmente enmarcados en los "equipos sociales" de implementación de la política pública y, por tanto, un nuevo rol de las ciencias sociales, tanto en la comprensión de la vivienda como en su producción.

\section{Referencias}

Álvarez, S. (2005). Los discursos minimistas sobre las necesidades básicas y los umbrales de ciudadanía como reproductores de la pobreza. En S. Álvarez (Comp.), Trabajo y Producción de la pobreza en Latinoamérica y el Caribe: estructuras, discursos y actores (pp. 239-274). Recuperado de http:/ / bibliotecavirtual. clacso.org.ar/ar/libros/crop/Trabprod.pdf

Borja, J. (2015). La vivienda popular, de la marginación a la ciudadanía.

En A. Rodríguez, p. Rodríguez \& A. Sugranyes (Eds), Con subsidio, sin derecho. La situación del derecho a una vivienda adecuada en Chile (pp. 245-263). Santiago: Ediciones Sur.

Bourdieu, p. (2010). Las estructuras sociales de la economía. Buenos Aires: Manantial.

Braudel, F. (1984). Civilización material, economía y capitalismo, siglos XVXVIII, Tomo I, Las estructuras de lo cotidiano: Lo posible y lo imposible [Traducido al español de Civilisation matérielle, économie et capitalisme, siècles XV-XVIII Tome1. Les structures du quotidiem: le possible et le imposible]. Madrid: Alianza.

Caquimbo, S. (2012). Editorial. Revista INVI, 24(65), 9-16. Recuperado de http://www.revistas.uchile.cl/index.php/INVI/article/ viewFile/8328/8078 
Castillo, M. \& Hidalgo, R. (2007). Introducción: Cien años de política habitacional en Chile. En M. Castillo \& R. Hidalgo (Eds.), 1906/2006 Cien años de vivienda en Chile (pp. 18-23). Santiago: Facultad de Arquitectura y Diseño Universidad Nacional Andrés Bello-Instituto de Geografía Pontificia Universidad Católica de Chile.

Ministerio de Desarrollo Social (2014, enero). Presentación Casen 2013 Vivienda: Síntesis de Resultados. Recuperado de http:/ / observatorio.ministeriodesarrollosocial.gob.cl/documentos/Casen2013_Vivienda.pdf

De Ramón, A. (2006). La población informal. Poblamiento de la periferia de Santiago de Chile, 1920-1970. En C. de Mattos, O. Figueroa, p. Bannen y D. Campos (Eds.), Santiago en EURE. Huellas de una metamorfosis metropolitana 1970 / 2000 (pp. 279-298). Santiago: Instituto de Estudios Urbanos y Territoriales, Pontificia Universidad Católica de Chile.

De Soussa, B. (2009). Epistemologías del sur. Ciudad de México: Siglo XXI Editores.

Ducci, M. E. (2007). La política habitacional como instrumento de desintegración social. Efectos de una política de vivienda exitosa. En M. Castillo y R. Hidalgo (Eds.), 1906/2006, Cien Años de Vivienda en Chile (pp. 107-123). Santiago: Facultad de Arquitectura y Diseño Universidad Nacional Andrés Bello, Instituto de Geografía Pontificia Universidad de Católica de Chile.

Engels, F. (1946). La cuestión de la vivienda [Traducido al español de Zur Wohnungsfrage]. Buenos Aires: Editorial Lautaro.

Equipo de Estudios Poblacionales CIDU (2006). Reivindicación Urbana y Lucha Política: los Campamentos de Pobladores en Santiago de Chile. En C. de Mattos, O. Figueroa, p. Bannen y D. Campos (Eds.), Santiago en EURE. Huellas de una metamorfosis metropolitana 1970 / 2000 (pp. 341-374). Santiago: Instituto de Estudios Urbanos y Territoriales, Pontificia Universidad Católica de Chile.

Escobar, A. (2007). La invención del tercer mundo. Construcción y deconstrucción del desarrollo. Caracas: Fundación Editorial el Perro y la Rana.

Espinoza, V. (1988). Para una historia de los pobres de la ciudad. Santiago: Ediciones Sur. 
Faletto, E. (1989). La especificidad del Estado en América Latina. Revista de la CEPAL, 38, 161-200.

Fernández, R. (2001). Las ciencias del ambiente construido y los estudios del hábitat y vivienda. Un nuevo marco para fortalecer la construcción transdisciplinar. Boletín del Instituto de la Vivienda Facultad de Arquitectura y Urbanismo Universidad de Chile, 43(16), 39-47.

Ffrench-Davis, R., López, E. y Arriagada, C. (2013). Crecimiento desigual económico y urbano: desafíos de políticas pro-equidad para las ciudades de las próximas décadas. En E. López, C. Arriagada, p. Jirón \& H. Eliash (Eds.), Chile urbano hacia el siglo XXI. Investigaciones y reflexiones de politica urbana desde la Universidad de Chile (pp. 149-159). Santiago: Editorial Universitaria.

Garretón, M. A. (2014). Las ciencias sociales en la trama de Chile y América Latina. Estudios sobre transformaciones politicas y movimiento social. Santiago: Lom.

Garretón, M. A., Cavarozzi, M., Cleaves, P., Gereffi, G. y Hartlyn, J. (2004). América Latina en el siglo 21. Hacia una nueva matriz sociopolítica. Santiago: Lom.

Giannini, H. (1987). La reflexión cotidiana. Hacia una arqueología de la experiencia. Santiago: Editorial Universitaria.

Haramoto, E. (2013). Notas sobre el diseño de la vivienda y de su entorno barrial y urbano. En E. López, C. Arriagada, p. Jirón y H. Eliash (Eds.), Chile urbano hacia el siglo XX. Investigaciones y reflexiones de politica urbana desde la Universidad de Chile (241248). Santiago: Editorial Universitaria.

Harvey, D. (2011). Breve historia del neoliberalismo. Madrid: Akal.

Heidegger, M. (1951). Construir, habitar, pensar [Traducido al español de Bauen, Wohnen, Denken] Recuperado de http:/ /www. geoacademia.cl/docente/mats / construir-habitar-pensar. pdf

Imilan W., Jirón p. e Iturra L. (2015). Más allá del barrio: habitar Santiago en la movilidad cotidiana. Revista Antropologías del Sur, 3, 97-103.

Lefebvre, H. (1972). Contra los tecnócratas [Traducido al español de Vers le cyberanthrope (Contre les technocrates)]. Buenos Aires: Granica. 
Matus, T. (s/f). Apuntes sobre intervención social. Recuperado de http://catalogo.uahurtado.cl/uhtbin/cgisirsi. exe/?ps=OfkiTnEwi4/BC/97850003/9

MIDEPLAN (2016, noviembre). Presentación Casen 2015 Vivienda y Entorno: Sintesis de Resultados. Santiago: Ministerio de Desarrollo Social. Recuperado de http:/ /observatorio.ministeriodesarrollosocial.gob.cl/casen-multidimensional/casen/ docs/CASEN_2015_Resultados_vivienda_y_entorno.pdf

MINVU (2007). Un siglo de políticas de vivienda y barrio. 2a ed. Santiago: Pehuén.

MINVU (2014). Vivienda Social en Copropiedad. Memoria de Tipologías en Condominios Sociales. Santiago: Ministerio de Vivienda y Urbanismo, Secretaría Ejecutiva de Barrios, Áreas de Estudios.

Moulian, T. (1997). Chile Actual. Anatomía de un Mito. Santiago: Lom.

Muñoz, T. (2011). Evolución del espacio doméstico en blocks de vivienda social. Autoconstrucción y vulnerabilidad en conjuntos de vivienda básica. Revista CIS, 15, 3-26.

Oficina del Alto Comisionado de las Naciones Unidas para los Derechos Humanos (2010). El Derecho a una vivienda adecuada. Ginebra: Naciones Unidas. Recuperado de http://www. ohchr.org/Documents /Publications /FS21_rev_1_Housing_sp.pdf

Ortiz, E. (2011). Producción social de vivienda y hábitat: bases conceptuales para una política pública. En Programa Regional de Vivienda y Hábitat \& Centro Cooperativo Sueco (Eds.), El camino posible: producción social del hábitat en América Latina (pp. 13-40). Montevideo: Ediciones Trilce.

Raposo, A. (2001). Estado, ethos social y politica de vivienda. Extraído el 8 de Agosto de 2012, de http:/ / www.ucentral.cl/fid/pdf/i paradigma_corvi/estado_ethos-pdf.

Rivas, A. (2013). Campamentos: factores socioespaciales vinculados a su persistencia. Tesis para optar al grado de Magíster en Urbanismo. Santiago: Facultad de Arquitectura y Urbanismo, Universidad de Chile.

Rodríguez, A. e Icaza, A. (1993). Procesos de expulsión de habitantes de bajos ingresos del centro de Santiago, 1981-1990. Proposiciones, 22, 138-172. Recuperado de http://www.sitiosur.cl/r. php?id=225. 
Rodríguez, A. y Sugranyes, A. (2004). El problema de vivienda de los "Con Techo". Revista EURE - Revista De Estudios Urbano Regionales, 30(91). Recuperado de http://www.eure.cl/ index.php/eure/article/view/1278

Rodríguez, p. (2016) El debilitamiento de lo urbano en Santiago, Chile. Eure, 42(125), 61-67. Recuperado de http:/ /www.scielo.cl/ pdf/eure/v42n125/art03.pdf

Romero, G. \& Mesías, R. (Coord.) (1999). La Participación en el diseño urbano y arquitectónico en la producción social del hábitat. Ciudad de México: Programa Iberoamericano de Ciencia y Tecnología para el Desarrollo CYTED.

Ruiz, C. (2013). Estado, alianzas sociales y modelos de desarrollo en América Latina hoy. Brasil, Chile y Argentina. Tesis para optar al grado de Doctor en Estudios Latinoamericanos. Santiago: Facultad de Filosofía y Humanidades, Universidad de Chile.

Ruiz, C. y Boccardo, G. (2014). Los chilenos bajo el neoliberalismo. Clases y Conflicto Social. Santiago: El Desconcierto.

Salgado, M. (2014). Reconstrucción de la vida cotidiana. La cara invisibilizada tras el terremoto y tsunami 2010. Cuadernos de Trabajo Social, 11, 53-60.

Smolka, M. \& Amborski, D. (2003). Captura de plusvalías para el desarrollo urbano: una comparación interamericana. Revista EURE, 88 (XXIX), 55-77.

Toledo, U. (2012). Socio-Fenomenología, el significado de la vida social cotidiana. Hualpén: Editoral Pentacopolitana.

Valenzuela, L. (2007). La Caja de Habitación Popular: el rostro cambiante de la vivienda en Chile 1936-1952. En M. Castillo y R. Hidalgo (Eds.), Cien años de vivienda en Chile. Santiago: Facultad de Arquitectura y Diseño Universidad Nacional Andrés Bello, Instituto de Geografía Pontificia Universidad de Católica de Chile. 